\title{
Estrone Sulfate
}

National Cancer Institute

\section{Source}

National Cancer Institute. Estrone Sulfate. NCI Thesaurus. Code C1091.

An aqueous substance that is the sulfate salt form of estrone. $(\mathrm{NCl})$ 